\title{
Analisis Penyebab dan Solusi Rekonsiliasi Finished Goods Menggunakan Hipotesis Statistik dengan Metode Pengujian Independent Sample T-Test di PT.Merck, Tbk.
}

\author{
Riana Magdalena ${ }^{1}$, Maria Angela Krisanti ${ }^{2}$ \\ 1,2Industrial Engineering Department, Atma Jaya Catholic University of Indonesia, Jakarta. \\ Email: riana.magdalena@atmajaya.ac.id ${ }^{1}$, maria.angela0801@gmail.com²
}

\begin{abstract}
Abstrak
PT. Merck, Tbk. merupakan perusahaan manufaktur yang bergerak di bidang pembuatan obat dengan memproduksi obat yang dituju untuk pasar over-the-counter (OTC) seperti Sangobion dan Neurobion dan juga pasar obat resep untuk rumah sakit. Berdasarkan Packaging Work Sheet (PWS) dari produk "X" yang diproduksi di PT. Merck, Tbk. ditemukan rekonsiliasi pada finished goods yang melebihi spesifikasi yang telah ditentukan sebelumnya oleh perusahaan. Rekonsiliasi merupakan perbedaan antara jumlah material yang masuk dengan material yang keluar sehingga jika rekonsiliasi melebihi yang seharusnya maka PT. Merck, Tbk. dapat mengalami kerugian karena jumlah material yang jadi tidak sesuai dengan material yang diproduksi. Berdasarkan permasalahan yang terjadi, maka penulis melakukan pengolahan data menggunakan hipotesis statistik dengan menggunakan metode pengujian Independent Sample T-Test untuk mengetahui proses produksi apa yang berpotensi menyebabkan rekonsiliasi pada finished goods produk " $X$ ". Dengan diketahuinya penyebab dari rekonsiliasi maka dapat dicari solusi yang tepat untuk mengatasi rekonsiliasi tersebut. Dari pengolahan data yang dilakukan, ditemukan bahwa terdapat perbedaan secara nyata antara berat rata-rata core tablet dengan berat coated tablet yang menandakan bahwa proses sugar coating berpengaruh secara signifikan terhadap variasi berat yang berpotensi menyebabkan rekonsiliasi. Oleh karena itu, ditentukan solusi yang tepat untuk memperbaiki proses tersebut.
\end{abstract}

Keywords: Rekonsiliasi, Hipotesis Statistik, Independent Sample T-Test, Uji-T

\section{PENDAHULUAN}

Seiring dengan berkembangnya zaman, industri manufaktur juga kian berkembang di berbagai bidang. Salah satu industri manufaktur yang sudah banyak berkembang di Indonesia adalah industri farmasi. Begitu banyak perusahaan yang bergerak di bidang pembuatan dan distribusi obat sehingga persaingan pada industri ini meningkat, dimana tiap perusahaan berusaha memberikan produk terbaik untuk konsumen. PT. Merck, Tbk. merupakan salah satu perusahaan yang bergerak di industri manufaktur bidang farmasi yang telah memulai proses produksinya di Indonesia sejak tahun 1974. Sebagai salah satu perusahaan manufaktur obat yang besar di Indonesia, menuntut PT. Merck, Tbk. 
untuk terus mengembangkan perusahaannya dan menghasilkan produk yang berkualitas.

Dalam industri manufaktur obat, tentunya kualitas merupakan hal yang sangatlah penting dan kritis mengingat kualitas dari obat yang diproduksi tersebut dapat mempengaruhi kesehatan dari orang yang mengkonsumsinya. Oleh karena itu, seluruh proses produksi dari obat, dimulai dari pengadaan material hingga pengemasan dan pendistribusian harus sangat diperhatikan agar kualitas dari produk tidak terganggu. Namun, pada Packaging Work Sheet dari salah satu produknya yaitu produk " $\mathrm{X}$ ", ditemukan deviasi pada rekonsiliasi finished products. Rekonsiliasi merupakan assessment perbedaan antara jumlah material yang diterima dengan jumlah material yang dihasilkan. Selain menyebabkan produk bervariasi pada beratnya dan turunnya kualitas, hal ini juga dapat menyebabkan kerugian material bagi perusahaan. Pada PWS ini ditemukan rekonsiliasi sebesar lebih dari 101\%, dimana seharusnya batas rekonsiliasi adalah 100\%. Rekonsiliasi didapatkan dari seluruh jumlah tablet yang diproduksi dibagi dengan jumlah tablet yang diterima. Jumlah tablet ini didapatkan dari berat tablet keseluruhan dibagi berat per tablet, dimana berat per tablet merupakan rata-rata yang diasumsikan dapat mewakili keseluruhan tablet. Namun, berat tablet memiliki variasi sehingga perlu diketahui proses manakah yang menyebabkan variasi terbesar karena kemungkinan besar proses inilah yang menyebabkan rekonsiliasi. Untuk mengetahui penyebabnya, maka perlu dilakukan penelitian dengan hipotesis statistik dengan menggunakan Independent Sample T-Test untuk meneliti lebih lanjut dari data yang dimiliki agar dapat diketahui apa yang menyebabkan deviasi ini untuk kemudian dianalisis dan didapatkan solusi yang dapat mengatasinya. Dari penelitian yang dilakukan ini, penulis akan memberikan saran dan masukan untuk PT. Merck, Tbk. untuk mengatasi rekonsiliasi finished goods yang terjadi.

\section{METODOLOGI}

Rekonsiliasi merupakan assessment terhadap perbedaan antara jumlah material yang diterima dan dihasilkan pada suatu proses atau rangkaian proses. Rekonsiliasi memiliki metode perhitungan sebagai berikut:

$$
\frac{(\mathrm{E}+\mathrm{F}+\mathrm{G})}{d} \times 100 \%=\text { final reconciliation }
$$

Sugar Coating merupakan tahapan dalam proses produksi obat, dimana suatu tablet yang telah jadi dilapisi oleh lapisan gula dimana lapisan ini berfungsi sebagai lapisan pelindung dari tablet untuk mencegah terbentuknya residual lembab yang akan mempengaruhi kualitas dari tablet dan menjaga kestabilannya. 
Proses sugar coating dilakukan merupakan proses semi otomasi karena walaupun menggunakan mesin coating, proses ini masih membutuhkan tangan operator saat penyemprotan atau penuangan lapisan gula.

Packing atau pengemasan merupakan proses untuk mengemas suatu produk menggunakan material kemas dengan tujuan melindungi produk tersebut dari kontaminasi dan juga agar produk tidak rusak saat proses pendistribusian

Proses pengemasan memiliki keterkaitan dengan rekonsiliasi, karena jika ditinjau pada formula rekonsiliasi, terdapat unsur F, yaitu jumlah tablet yang ditolak selama proses blister. Karena adanya tablet yang di reject maka jumlah tablet yang telah menjadi produk jadi juga akan berubah dari perhitungan teoritisnya sehingga berpengaruh pada rekonsiliasi.

Menurut Nasution [3], hipotesis adalah suatu pernyataan tentatif yang merupakan dugaan mengenai apa saja yang sedang kita amati dalam usaha untuk memahaminya. Hipotesis statistic sendiri adalah suatu anggapan atau pernyataan, yang mungkin benar atau mungkin juga salah, mengenai satu populasi atau lebih. Hipotesis yang dirumuskan dengan harapan akan ditolak memiliki istilah hipotesis nol yang dilambangkan dengan $\mathrm{H}_{0}$. Penolakan $\mathrm{H}_{0}$ akan mengakibatkan diterimanya hipotesis alternatif yang dilambangkan dengan $\mathrm{H}_{1}$.

Uji-T atau T-Test adalah salah metode pengujian dari uji statistik parametrik.. Menurut Ghozali [1,2], uji statistik t adalah suatu uji yang menunjukkan seberapa jauh pengaruh satu variable independent secara individual dalam menerangkan variabel dependen. Pengujian statistik $t$ atau t-test ini dilakukan dengan menggunakan tingkat signifikansi sebesar $0,05 \quad(\alpha=5 \%)$. Penerimaan atau penolakan uji hipotesis ini dilakukan dengan kriteria sebagai berikut [5]:

1) Jika nilai siginifikan $>0,05$, maka hipotesis nol $\left(\mathrm{H}_{0}\right)$ diterima dan hipotesis alternatif $\left(\mathrm{H}_{1}\right)$ ditolak. Hal ini berarti, secara parsial variabel independen tersebut tidak mempunyai pengaruh yang signifikan terhadap variable dependen.

2) Jika nilai signifikan $<0,05$ maka hipotesis nol $\left(\mathrm{H}_{0}\right)$ ditolak dan hipotesis alternatif $\left(\mathrm{H}_{1}\right)$ diterima. Hal ini berarti secara parsial variavel independen tersebut mempunyai pengaruh yang signifikan terhadap variable dependen.

Rumus dari uji-t adalah sebagai berikut: [2,4]:

$$
t=\frac{\overline{x_{1}}-\overline{x_{2}}}{\sqrt{\frac{\left(n_{1}-1\right) s_{1}^{2}+\left(n_{2}-1\right) s_{2}^{2}}{n_{1}+n_{2}-2}\left(\frac{1}{n_{1}}+\frac{1}{n_{2}}\right)}}
$$


Keterangan:

$\overline{x_{1}}=$ rata - rata sampel 1

$\overline{x_{2}}=$ rata - rata sampel 2

$n_{1}=$ jumlah sampel 1

$n_{2}=$ jumlah sampel 2

$s_{1}=$ simpangan baku sampel 1

$s_{2}=$ simpangan baku sampel 2

\section{ANALISIS DAN PEMBAHASAN}

Data yang dikumpulkan adalah data rekonsiliasi, data berat tablet sebenarnya, berat coated tablet, berat core tablet dan jumlah tablet jadi, reject dan diterima. Data yang ada merupakan data produk "X" batch 274 - 309.

Tabel 1. Rekonsiliasi

\begin{tabular}{ccccccccc}
\hline Batch & $\begin{array}{c}\text { Berat } \\
\text { Terima } \\
\mathbf{( k g )}\end{array}$ & $\begin{array}{c}\text { Berat } \\
\text { Tablet } \\
\text { Sebenar- } \\
\text { nya (mg) }\end{array}$ & $\begin{array}{c}\text { Jumlah } \\
\text { tablet } \\
\text { diterima }\end{array}$ & $\begin{array}{c}\text { Check } \\
\text { Jumlah } \\
\text { Tablet } \\
\text { Diterima }\end{array}$ & $\begin{array}{c}\text { Reject } \\
\mathbf{( k g )}\end{array}$ & $\begin{array}{c}\text { Jum- } \\
\text { lah } \\
\text { Re } \\
\text {-ject }\end{array}$ & $\begin{array}{c}\text { Total } \\
\text { Produk } \\
\text { Jadi }\end{array}$ & Rekonsiliasi \\
\hline 309 & 80.27 & 270.8 & 296418 & 296418 & 0.18 & 665 & 287620 & 97 \\
\hline 308 & 80 & 276 & 289855 & 289855.1 & 0.2 & 725 & 291920 & 101 \\
\hline 307 & 79.24 & 272.7 & 290575 & 290575.7 & 0.13 & 477 & 287020 & 99 \\
\hline 306 & 79.35 & 271 & 292804 & 292804.4 & 0.61 & 2251 & 288820 & 99 \\
\hline 305 & 77.89 & 275.4 & 282824 & 282825 & 0.2 & 726 & 283320 & 100 \\
\hline 304 & 79.36 & 270.4 & 293491 & 293491.1 & 0.18 & 666 & 292520 & 100 \\
\hline 303 & 77.48 & 275 & 281745 & 281745.5 & 0.57 & 2073 & 282800 & 101.1 \\
\hline 302 & 78.27 & 271.6 & 288181 & 288181.1 & 0.16 & 589 & 282200 & 98.1 \\
\hline 301 & 77.69 & 272 & 285625 & 285625 & 0.23 & 846 & 275900 & 7 \\
\hline 300 & 80.74 & 271 & 297933 & 297933.6 & 0.16 & 590 & 292500 & 98.4 \\
\hline 299 & 79.91 & 272.3 & 293463 & 293463.1 & 0.12 & 441 & 293100 & 100.2 \\
\hline 298 & 81 & 277.6 & 291786 & 291786.7 & 0.1 & 360 & 292400 & 100.3 \\
\hline
\end{tabular}


(Civil Engineeering, Elektrical Engineeering and Industrial Engineeering)

Vol. 16, No : 1, April 2019 , p-ISSN:1907-5243, e-ISSN: 2655-8416

Tabel 2. Rekonsiliasi

\begin{tabular}{|c|c|c|c|c|c|c|c|c|}
\hline Batch & $\begin{array}{c}\text { Berat } \\
\text { Terima } \\
\text { (kg) }\end{array}$ & $\begin{array}{l}\text { Berat Tablet } \\
\text { Sebenarnya } \\
\quad(\mathrm{mg})\end{array}$ & $\begin{array}{c}\text { Jumlah } \\
\text { tablet } \\
\text { diterima }\end{array}$ & $\begin{array}{c}\text { Check } \\
\text { Jumlah } \\
\text { Tablet } \\
\text { Diterima }\end{array}$ & $\begin{array}{c}\text { Reject } \\
\text { (kg) }\end{array}$ & $\begin{array}{l}\text { Jumlah } \\
\text { Reject }\end{array}$ & $\begin{array}{c}\text { Total } \\
\text { Produk } \\
\text { Jadi }\end{array}$ & Rekonsiliasi \\
\hline 297 & 81 & 278 & 291366 & 291366.9 & 0.26 & 935 & 291300 & 100.3 \\
\hline 296 & 81 & 275.7 & 293797 & 293797.6 & 0.15 & 544 & 293100 & 99.9 \\
\hline 295 & 79.6 & 276 & 288405 & 288405.8 & 0.25 & 906 & 292550 & 101.8 \\
\hline 294 & 79.96 & 275 & 290763 & 290763.6 & 0.14 & 509 & 291300 & 100.4 \\
\hline 293 & 80.1 & 270.9 & 295681 & 295681.1 & 0.21 & 775 & 295600 & 100.2 \\
\hline 292 & 80.4 & 271.6 & 296023 & 296023.6 & 0.11 & 405 & 294100 & 99.5 \\
\hline 291 & 81 & 276.3 & 293159 & 293159.6 & 0.17 & 615 & 295100 & 100.9 \\
\hline 290 & 79.75 & 271.1 & 294171 & 294171.9 & 0.13 & 480 & 294600 & 100.3 \\
\hline 289 & 80.7 & 272.46 & 296190 & 296190.3 & 0.16 & 587 & 294900 & 99.8 \\
\hline 288 & 80.75 & 272.8 & 296004 & 296004.4 & 0.09 & 330 & 294900 & 99.7 \\
\hline 287 & 84.5 & 297.35 & 284416 & 284176.9 & 0.11 & 370 & 280700 & 98.8 \\
\hline 286 & 81.7 & 276.87 & 295084 & 295084.3 & 0.13 & 470 & 293400 & 100 \\
\hline 285 & 80.6 & 274.8 & 293304 & 293304.2 & 0.0905 & 329 & 290500 & 99.16 \\
\hline 284 & 74.8 & 296.5 & 252276 & 252276.6 & 1.82 & 6138 & 249300 & 103.62 \\
\hline 283 & 81.5 & 276.2 & 295076 & 295076 & 1.06 & 3838 & 290600 & 99.78 \\
\hline 282 & 80.1 & 275.1 & 291166 & 291166.8 & 0.3 & 1091 & 289400 & 99.76 \\
\hline 281 & 81.95 & 284 & 288556 & 288556.3 & 0.25 & 880 & 291800 & 101.43 \\
\hline 280 & 78.7 & 281.9 & 279177 & 279177 & 0.37 & 1313 & 279800 & 100.69 \\
\hline 279 & 75.2 & 269.4 & 279138 & 279138.8 & 0.1 & 371 & 288100 & 103.83 \\
\hline 278 & 82.8 & 279.5 & 296243 & 296243.3 & 0.09 & 322 & 296300 & 100.12 \\
\hline 277 & 82.6 & 275.8 & 299492 & 299492.4 & 0.08 & 290 & 298300 & 99.69 \\
\hline 276 & 82.9 & 277.8 & 298416 & 298416.1 & 0.1 & 360 & 298056 & 100.01 \\
\hline 275 & 81.5 & 278 & 293165 & 293165.5 & 0.05 & 180 & 290300 & 99.27 \\
\hline 274 & 80.9 & 277.3 & 291741 & 291741.8 & 0.094 & 339 & 293500 & 100.7 \\
\hline
\end{tabular}




\section{Jurnal TEKNO}

(Civil Engineeering, Elektrical Engineeering and Industrial Engineeering) Vol. 16, No : 1, April 2019 , p-ISSN:1907-5243, e-ISSN: 2655-8416

Tabel 3. Core Tablet Weight, Coated Weight, Original Tablet Weight

\begin{tabular}{|c|c|c|c|}
\hline Batch & Core Tablet Weight (mg) & $\begin{array}{l}\text { Coated Weight } \\
\text { (mg) }\end{array}$ & $\begin{array}{l}\text { Original Tablet Weight } \\
\text { (mg) }\end{array}$ \\
\hline 309 & 159.60 & 270.8 & 270.8 \\
\hline 308 & 159.87 & 276.3 & 276 \\
\hline 307 & 160.53 & 272.7 & 272.7 \\
\hline 306 & 160.10 & 271.85 & 271 \\
\hline 305 & 160.47 & 275.4 & 275.4 \\
\hline 304 & 160.53 & 270.4 & 270.4 \\
\hline 303 & 159.87 & 275 & 275 \\
\hline 302 & 160.60 & 271.65 & 271.6 \\
\hline 301 & 160.73 & 272 & 272 \\
\hline 300 & 160.97 & 271 & 271 \\
\hline 299 & 159.97 & 272.3 & 272.3 \\
\hline 298 & 160.77 & 277.6 & 277.6 \\
\hline 297 & 161.13 & 278 & 278 \\
\hline 296 & 159.67 & 273.3 & 275.7 \\
\hline 295 & 161.80 & 276 & 276 \\
\hline 294 & 160.63 & 275.1 & 275 \\
\hline 293 & 160.03 & 271.2 & 270.9 \\
\hline 292 & 159.87 & 272.5 & 271.6 \\
\hline 291 & 161.00 & 272.3 & 276.3 \\
\hline 290 & 159.37 & 271.6 & 271.1 \\
\hline 289 & 160.37 & 273.8 & 272.46 \\
\hline 288 & 161.43 & 274.6 & 272.8 \\
\hline 287 & 161.90 & 289.5 & 297.35 \\
\hline 286 & 159.93 & 272.8 & 276.87 \\
\hline 285 & 162.37 & 275.4 & 274.8 \\
\hline 284 & 161.97 & 282.6 & 296.5 \\
\hline 283 & 162.00 & 272.2 & 276.2 \\
\hline 282 & 160.70 & 278.4 & 275.1 \\
\hline 281 & 159.80 & 279.4 & 284 \\
\hline 280 & 159.37 & 276.8 & 281.9 \\
\hline 279 & 160.20 & 270 & 269.4 \\
\hline 278 & 160.10 & 279.2 & 279.5 \\
\hline 277 & 159.87 & 273.6 & 275.8 \\
\hline 276 & 160.20 & 274.5 & 277.8 \\
\hline 275 & 159.43 & 273.6 & 278 \\
\hline 274 & 161.20 & 278.7 & 277.3 \\
\hline
\end{tabular}

40 | Analisis Penyebab dan Solusi Rekonsiliasi Finished Goods Menggunakan Hipotesis Statistik dengan Metode Pengujian Independent Sample T-Test di PT.Merck, Tbk. 


\subsection{Proses Sugar Coating}

Berat core tablet adalah berat tablet setelah proses tableting dan sebelum proses sugar coating. Sedangkan berat tablet sebenarnya adalah berat tablet setelah proses sugar coating.

Langkah-langkah pengujian hipotesis rataan 2 sampel ini adalah sebagai berikut:

1) $\mathrm{H}_{0}$ : Berat rata-rata core tablet sama dengan berat rata-rata coated tablet

2) $\mathrm{H}_{1}$ : Berat rata-rata core tablet tidak sama dengan berat rata-rata coated tablet

3) $\alpha=5 \%$

4) Daerah kritis: $\mathrm{t}<-\mathrm{t}_{(\alpha / 2 ; \mathrm{n} 1+\mathrm{n} 2-2)}$ atau $\mathrm{t}>\mathrm{t}_{(\alpha / 2 ; \mathrm{n} 1+\mathrm{n} 2-2)}$

$\mathrm{t}<-\mathrm{t}_{(0.025 ; \mathrm{n} 1+\mathrm{n} 2-2)}$ atau $\mathrm{t}>\mathrm{t}_{(0.025 ; \mathrm{n} 1+\mathrm{n} 2-2)}$

$\mathrm{t}<-\mathrm{t}_{(0.025 ; 70)}$ atau $\mathrm{t}>\mathrm{t}_{(0.025 ; 70)}$

$\mathrm{t}<-\mathrm{t}_{1,9944}$ atau $\mathrm{t}>\mathrm{t}_{1,9944}$

5) Nilai $\mathrm{t}=171.83$

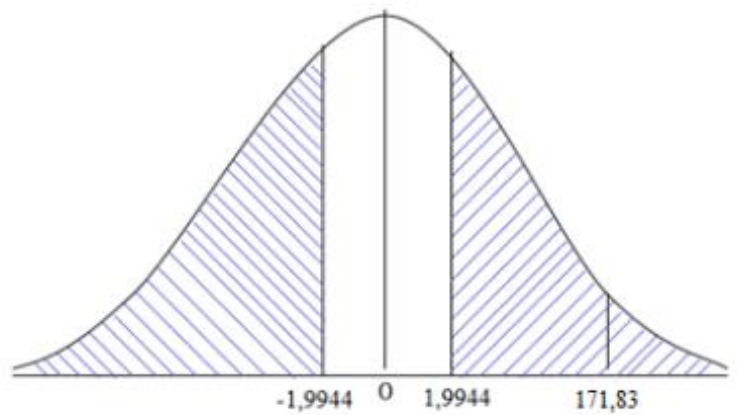

Gambar 1. Kurva Uji -T Berat Core Tablet dengan Berat Coated Tablet 


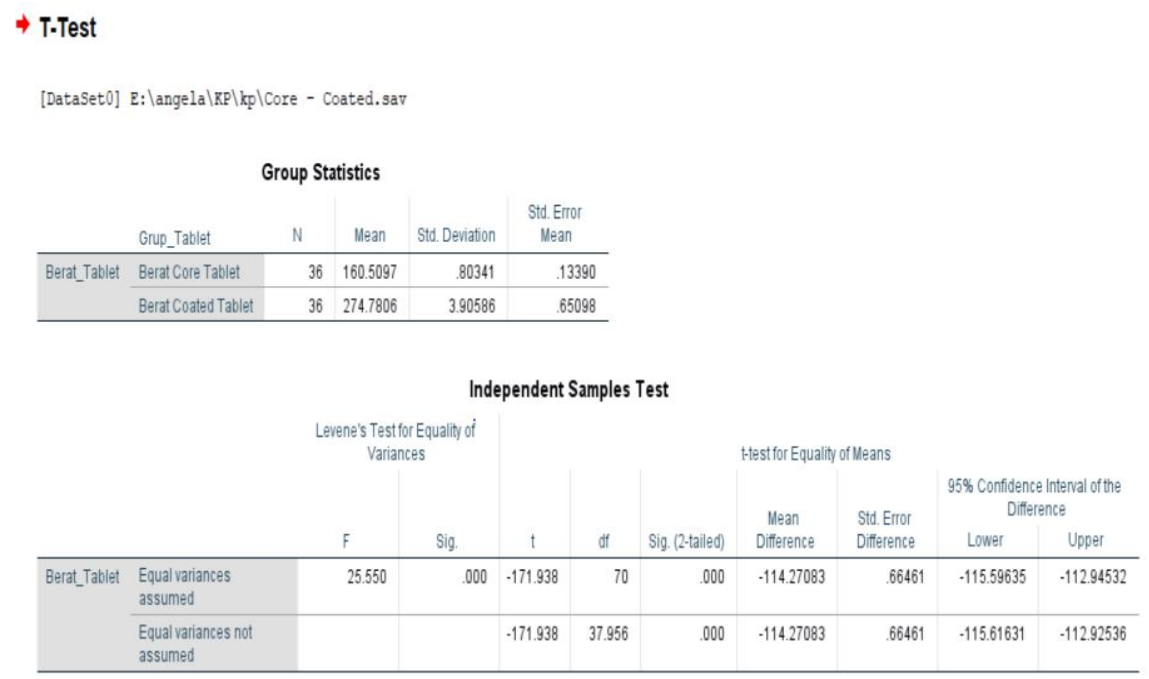

Gambar 2. Hasil Uji -T Berat Core Tablet dengan Berat Coated Tablet dengan Software SPSS

Dari hasil perhitungan dapat ditarik kesimpulan bahwa $\mathrm{H} 0$ ditolak karena nilai t-hitung lebih besar dari t-tabel $(171,83>1,9944)$, sehingga berat rata-rata core tablet tidak sama dengan berat rata-rata tablet sebenarnya.Dari hasil pengujian SPSS ini dapat dilihat bahwa rata-rata berat core tablet dengan berat tablet sebenarnya berbeda secara signifikan karena hasil dari Sig.(2-tailed) lebih kecil dari $\alpha(0<0.025)$ sehingga $\mathrm{H}_{0}$ ditolak.

\subsection{Proses Packing Blister}

Dari perhitungan sebelumnya telah diketahui bahwa terdapat perbedaan signifikan antara berat core tablet dengan berat coated tablet (setelah proses sugar coating). Maka sekarang akan dilakukan perhitungan apakah ada perbedaan antara berat coated tablet dengan berat tablet sebenarnya.

Langkah-langkah pengujian hipotesisnya adalah sebagai berikut:

1) $\mathrm{H}_{0}$ : Berat rata-rata coated tablet sama dengan berat rata-rata tablet aktual

2) $\mathrm{H}_{1}$ : Berat rata-rata coated tablet tidak sama dengan berat rata-rata tablet sebenarnya

3) $\alpha=5 \%$

4) Daerah kritis: $\mathrm{t}<-\mathrm{t}_{(\alpha / 2 ; \mathrm{n} 1+\mathrm{n} 2-2)}$ atau $\mathrm{t}>\mathrm{t}_{(\alpha / 2 ; \mathrm{n} 1+\mathrm{n} 2-2)}$

$\mathrm{t}<-\mathrm{t}_{(0.025 ; \mathrm{n} 1+\mathrm{n} 2-2)}$ atau $\mathrm{t}>\mathrm{t}_{(0.025 ; \mathrm{n} 1+\mathrm{n} 2-2)}$

$\mathrm{t}<-\mathrm{t}_{(0.025 ; 70)}$ atau $\mathrm{t}>\mathrm{t}_{(0.025 ; 70)}$

$\mathrm{t}<-\mathrm{t}_{1,9944}$ atau $\mathrm{t}>\mathrm{t}_{1,9944}$

5) Nilai $t=1,02$

42 | Analisis Penyebab dan Solusi Rekonsiliasi Finished Goods Menggunakan Hipotesis Statistik dengan Metode Penguizan Independent Sample T-Test di PT.Merck, Tbk. 


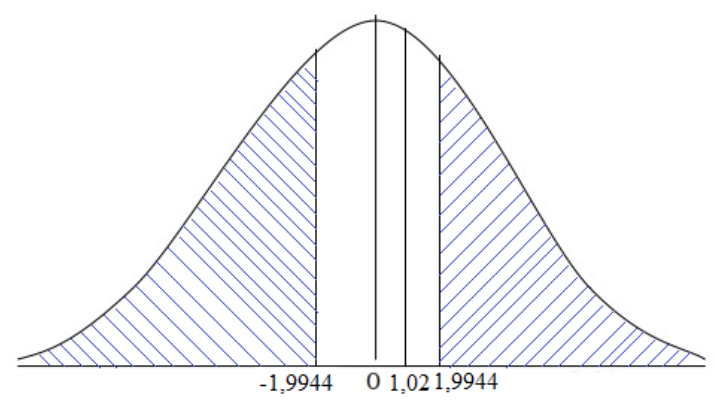

\section{Gambar 3. Kurva Uji-T Berat Coated Tablet dengan Berat Tablet Sebenarnya}

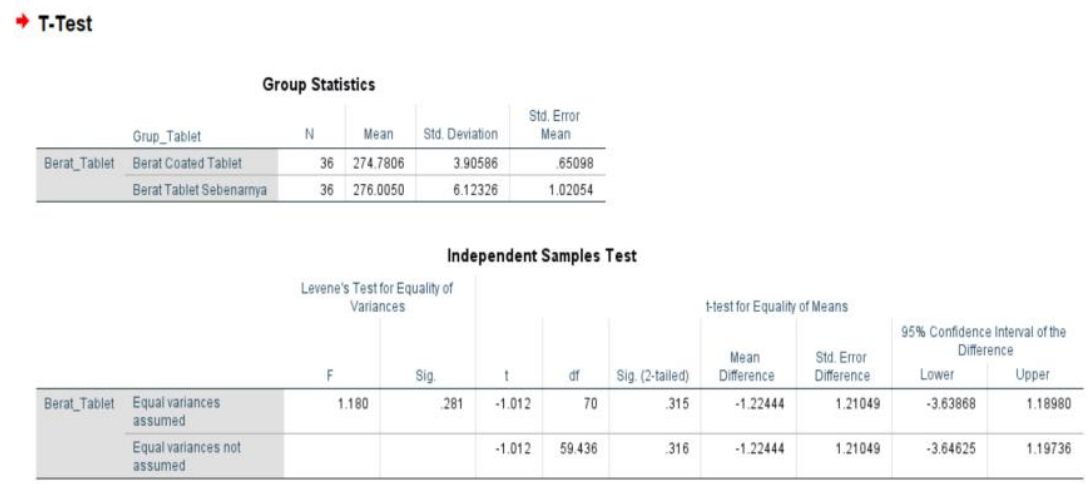

Gambar 4. Hasil Uji-T Berat Coated Tablet dengan Berat Tablet Sebenarnya dengan Software SPSS

Dari hasil perhitungan dapat ditarik kesimpulan bahwa $\mathrm{H}_{0}$ diterima karena nilai t-hitung lebih kecil dari t-tabel $(1,02<1,9944)$, sehingga berat rata-rata coated tablet sama dengan berat rata-rata tablet sebenarnya.

Dari hasil pengujian SPSS ini dapat dilihat bahwa rata-rata berat core tablet dengan berat tablet sebenarnya tidak berbeda secara signifikan karena hasil dari Sig.(2-tailed) lebih besar dari $\alpha(0,315>0,025)$ sehingga $\mathrm{H}_{0}$ diterima.

\subsection{Proses Packing}

Perlu dilakukan uji perbandingan antara variabel $(\mathrm{E}+\mathrm{F}+\mathrm{G})$ dengan $d$ untuk melihat apakah ada proses yang menyebabkan variasi setelah pengemasan. Dari data, tidak ada tablet yang ditolak selama inspeksi visual 
sehingga yang dibandingkan hanya $(\mathrm{F}+\mathrm{G})$ yang menjadi Jumlah Tabel Diproduksi pada tabel 8 dibawah ini.

Berikut adalah langkah-langkah yang dilakukan:

1) $\mathrm{H}_{0}$ : Jumlah rata-rata tablet yang diproduksi sama dengan jumlah rata-rata tablet yang diterima.

2) $\mathrm{H}_{1}$ : Jumlah rata-rata tablet yang diproduksi tidak sama dengan jumlah rata-rata tablet yang diterima.

3) $\alpha=5 \%$

4) Daerah kritis: $\mathrm{t}<-\mathrm{t}_{(\alpha / 2 ; \mathrm{n} 1+\mathrm{n} 2-2)}$ atau $\mathrm{t}>\mathrm{t}_{(\alpha / 2 ; \mathrm{n} 1+\mathrm{n} 2-2)}$

$$
\begin{aligned}
& \mathrm{t}<-\mathrm{t}_{(0.025 ; \mathrm{n} 1+\mathrm{n} 2-2)} \text { atau } \mathrm{t}>\mathrm{t}_{(0.025 ; \mathrm{n} 1+\mathrm{n} 2-2)} \\
& \mathrm{t}<-\mathrm{t}_{(0.025 ; 70)} \text { atau } \mathrm{t}>\mathrm{t}_{(0.025 ; 70)} \\
& \mathrm{t}<-\mathrm{t}_{1,9944} \text { atau } \mathrm{t}>\mathrm{t}_{1,9944}
\end{aligned}
$$

5) Nilai $t=0.103$

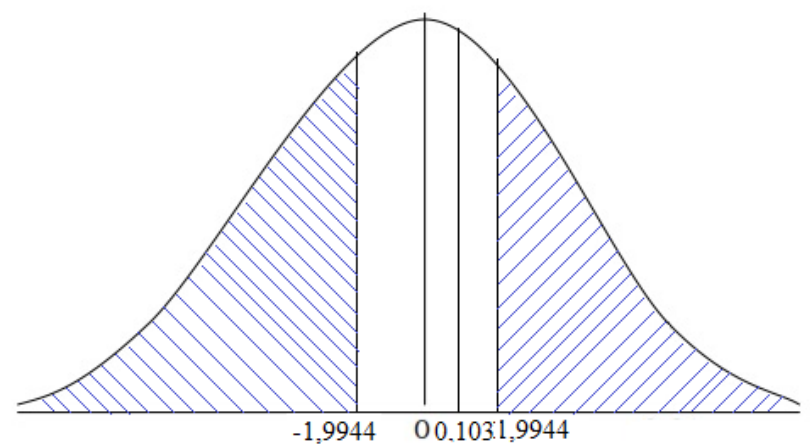

Gambar 4. Kurva Uji -T Jumlah Tablet Diproduksi dengan Jumlah Tablet Diterima 


\begin{tabular}{|c|c|c|c|c|c|}
\hline \multicolumn{6}{|c|}{ Group Statistics } \\
\hline & Grup_Tablet & $\mathrm{N}$ & Mean & Std. Deviation & $\begin{array}{l}\text { Std. Enor } \\
\text { Mean }\end{array}$ \\
\hline \multirow[t]{2}{*}{ Tablet } & Tablet Diproduksi & 36 & 290289.2222 & 7848.13550 & 1308.02258 \\
\hline & Tablet Diterima & 36 & 290486.3611 & 8334.62061 & 1389.10343 \\
\hline
\end{tabular}

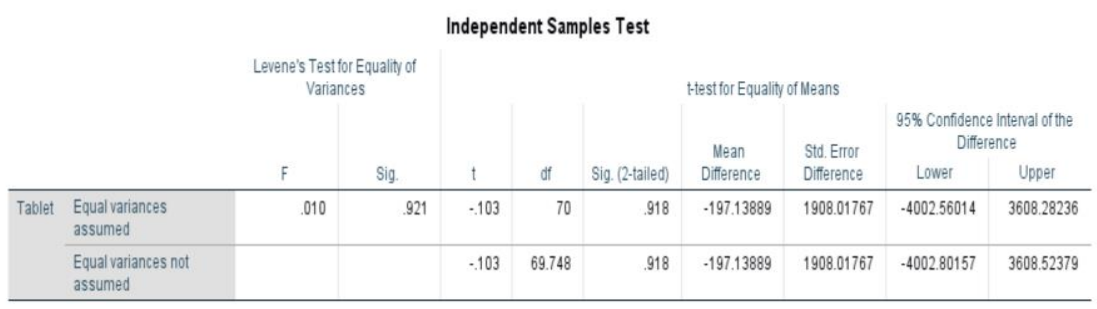

Gambar 5. Hasil Uji -T Jumlah Tablet Diproduksi dengan Jumlah Tablet Diterima dengan Software SPSS

Dari hasil perhitungan dapat ditarik kesimpulan bahwa $\mathrm{H}_{0}$ diterima karena nilai thitung lebih kecil dari t-tabel $(0,103<1,9944)$, sehingga Jumlah rata-rata tablet yang diproduksi dapat dikatakan sama dengan jumlah rata-rata tablet yang diterima. Dari hasil pengujian SPSS ini dapat dilihat bahwa jumlah tablet diproduksi dengan jumlah tablet diterima tidak berbeda secara signifikan karena hasil dari Sig. (2-tailed) lebih besar dari $\alpha(0,918>0,025)$ sehingga $\mathrm{H}_{0}$ diterima.

Berdasarkan penelitian yang dilakukan di PT. Merck, Tbk. didapatkan data yang menunjukkan rekonsiliasi yang out of specification pada finished goods produk "X". Rekonsiliasi merupakan perbedaan antara jumlah material masuk dengan material yang keluar dimana nilai rekonsiliasi yang ideal adalah 100\%, dengan spesifikasi maksimal 101\%. Namun pada Packaging Work Sheet (PWS) dari produk "X" dari batch 274 - 309, ditemukan nilai rekonsiliasi yang lebih dari 101\%.

Dari data yang didapatkan, dilakukan pengolahan data dari proses sugar coating dengan asumsi proses sebelum sugar coating tidak menyebabkan variasi pada berat tablet. Hal ini karena proses sebelum sugar coating merupakan proses yang telah terotomasi dan akan menghasilkan produk dengan spesifikasi yang sesuai dan konstan. Namun, proses sugar coating masih merupakan proses yang semi-otomasi karena penuangan lapisan gula dilakukan secara manual oleh personel dan hanya bergantung dari keterampilan personel tersebut sehingga kemungkinan terjadi buman error cukup besar.

Oleh karena itu, dilakukan pengolahan data dengan hipotesis statistik menggunakan pengujian Independent Sample T-Test untuk melihat proses manakah 
yang menyebabkan variasi pada berat tablet karena hal ini merupakan kemungkinan terbesar rekonsiliasi terjadi dan faktor apakah yang menyebabkan deviasi pada rekonsiliasi finished goods produk "X". Pertama, dilakukan pengujian perbandingan antara berat core tablet dengan berat coated tablet. Core tablet adalah tablet yang telah melewati proses tableting sebelum dilapisi oleh lapisan gula, dan coated tablet adalah tablet yang telah melewati proses sugar coating. Pengujian ini dilakukan untuk melihat apakah terdapat perbedaan antara rata-rata berat coated tablet dengan core tablet sehingga dapat diketahui apakah proses sugar coating mempengaruhi berat tablet secara signifikan atau tidak. Tingkat signifikansi yang digunakan adalah $0,05 \quad(\alpha=5 \%)$, namun karena pengujiannya merupakan pengujian 2 arah sehingga nilainya menjadi 0,025 sehingga daerah kritisnya menjadi $\mathrm{t}<-\mathrm{t}_{1,9944}$ atau $\mathrm{t}>\mathrm{t}_{1,9944}$. Setelah dilakukan perhitungan didapatkan hasil nilai t hitung sebesar 171,83 dimana nilai t hitung lebih besar dari t tabel $(171,83$ $>1,9944)$ dan menyebabkan $\mathrm{H}_{0}$ ditolak karena thitung jatuh pada daerah kritis.

Penolakan $\mathrm{H}_{0}$ ini menandakan bahwa berat rata-rata core tablet tidak sama dengan berat rata-rata coated tablet dan terdapat perbedaan yang signifikan antara kedua berat ini. Selain perhitungan manual, dilakukan pengujian dengan menggunakan software SPSS dan didapatkan hasil dimana Sig.(2-tailed) lebih kecil dari $\alpha(0<$ 0.025) sehingga $\mathrm{H}_{0}$ ditolak. Selain itu, dari hasil pengujian dapat dilihat bahwa nilai standar deviasi dari berat coated tablet menunjukkan hasil yang cukup besar yaitu 3,90586 sedangkan berat core tablet hanya memiliki standar deviasi sebesar 0,80341 sehingga berat coated tablet memiliki sebaran data yang luas dan data yang bervariasi. Hasil pengujian ini menunjukkan bahwa proses sugar coating memang menyebabkan variasi pada berat tablet.

Pengujian kedua dilakukan untuk berat coated tablet dengan berat tablet sebenarnya. Tablet sebenarnya adalah tablet yang telah melewati proses sugar coating dan proses packing blister. Pengujian ini untuk melihat apakah terdapat perbedaan secara nyata antara kedua berat tablet ini untuk mengetahui apakah proses packing blister mempengaruhi berat tablet secara signifikan. Tingkat signifikansi yang digunakan adalah $0,05(\alpha=5 \%)$, namun karena pengujiannya merupakan pengujian 2 arah sehingga nilainya menjadi 0,025 sehingga daerah kritisnya menjadi $\mathrm{t}<-\mathrm{t}_{1,9944}$ atau $\mathrm{t}>\mathrm{t}_{1,9944}$. Setelah dilakukan perhitungan didapatkan hasil nilai t hitung sebesar 1,02 dimana nilai t hitung lebih kecil dari $\mathrm{t}$ tabel $(1,02<1,9944)$ dan menyebabkan $\mathrm{H}_{0}$ diterima karena t hitung tidak jatuh pada daerah kritis.

Penerimaan $\mathrm{H}_{0}$ ini menandakan bahwa berat rata-rata tablet sebenarnya sama dengan berat rata-rata coated tablet karena tidak terdapat cukup bukti untuk mengatakan kedua berat ini tidak sama sehingga berat rata-rata tablet sebenarnya dengan berat coated tablet dapat dikatakan tidak berbeda secara nyata. Selain perhitungan manual, dilakukan pengujian dengan menggunakan software SPSS dan 46 | Analisis Penyebab dan Solusi Rekonsiliasi Finished Goods Menggunakan Hipotesis Statistik dengan Metode Pengujian Independent Sample T-Test di PT.Merck, Tbk. 
didapatkan hasil dimana Sig.(2-tailed) lebih besar dari $\alpha(0,315>0.025)$ sehingga $\mathrm{H}_{0}$ diterima. Selain itu, dari hasil pengujian dapat dilihat bahwa nilai standar deviasi dari berat tablet sebenarnya menunjukkan hasil yang cukup besar yaitu 6,12326 sehingga berat tablet sebenarnya memiliki sebaran data yang luas dan data yang bervariasi. Walaupun berat tablet sebenarnya bervariasi, hasil pengujian ini menunjukkan bahwa proses packing tidak mempengaruhi berat tablet secara signifikan.

Pengujian terakhir dilakukan pada perhitungan rekonsiliasi yaitu setelah proses packing sekunder. Dimana dilakuan pengujian perbandingan antara faktor $(\mathrm{E}+\mathrm{F}+\mathrm{G})$ dengan $d$. E adalah jumlah tablet yang ditolak selama inspeksi visual, $\mathrm{F}$ adalah jumlah tablet yang ditolak selama proses blister, $G$ adalah jumlah tablet sebagai produk jadi dan $d$ adalah jumlah tablet yang diterima. Pada kasus ini tidak terdapat tablet yang ditolak selama inspeksi visual sehingga yang diperhitungkan hanyalah faktor $(F+G)$ dengan $d$. Jumlah tablet yang diterima adalah jumlah tablet yang telah melewati packing sekunder dan menjadi finished goods. Pengujian ini dilakukan untuk melihat apakah faktor-faktor ini mempengaruhi rekonsiliasi secara signifikan. Tingkat signifikansi yang digunakan adalah $0,05 \quad(\alpha=5 \%)$, namun karena pengujiannya merupakan pengujian 2 arah sehingga nilainya menjadi 0,025 sehingga daerah kritisnya menjadi $\mathrm{t}<-\mathrm{t}_{1,9944}$ atau $\mathrm{t}>\mathrm{t}_{1,9944}$. Setelah dilakukan perhitungan didapatkan hasil nilai t hitung sebesar 0,103 dimana nilai $t$ hitung lebih kecil dari $\mathrm{t}$ tabel $(0,103<1,9944)$ dan menyebabkan $\mathrm{H}_{0}$ diterima karena t hitung tidak jatuh pada daerah kritis.

Penerimaan $\mathrm{H}_{0}$ berarti berat jumlah rata-rata tablet yang diproduksi sama dengan jumlah rata-rata tablet yang diterima karena tidak terdapat cukup bukti untuk mengatakan kedua jumlah ini tidak sama sehingga jumlah rata-rata tablet yang diproduksi dengan jumlah tablet yang diterima dapat dikatakan tidak berbeda secara nyata. Selain perhitungan manual, dilakukan pengujian dengan menggunakan software SPSS dan didapatkan hasil dimana Sig.(2-tailed) lebih besar dari $\alpha(0,918>0.025)$ sehingga $\mathrm{H}_{0}$ diterima. Hasil pengujian ini menunjukkan bahwa proses packing sekunder tidak mempengaruhi jumlah tablet secara signifikan.

Dari pengujian yang dilakukan, dapat dilihat bahwa proses yang menyebabkan variasi pada berat hanya proses sugar coating. Setelah dilakukan pengolahan data, dapat dilihat bahwa proses blister packing dan packing sekunder tidak memberikan variasi secara signifikan sehingga terjadinya deviasi juga hanya diakibatkan oleh variasi berat yang terjadi pada coated tablet. Dapat dilihat bahwa proses sugar coating berpotensi memberikan variasi paling besar pada produk. Setelah ditemukan penyebab terjadinya variasi dan deviasi maka diperlukan solusi terkait proses sugar coating. Solusi yang dapat dilakukan adalah mengganti proses dari semi-otomasi menjadi terotomasi sepenuhnya, karena terjadinya variasi disebabkan oleh faktor 
manusia pada proses tersebut dimana tidak terdapat standar prosedur yang jelas mengenai penuangan lapisan gula dan hanya bergantung pada pengalaman dan keterampilan personel tersebut. Tetapi solusi ini juga tidak mudah karena akan menambahkan pada biaya peralatan dimana perlu dilakukan perhitungan lebih lanjut apakah penggantian mesin layak atau tidak. Solusi lain yang dapat dilakukan adalah mengganti spesifikasi dari rekonsiliasi agar spesifikasi tersebut dapat mencakup seluruh hasil rekonsiliasi finished goods.

\section{KESIMPULAN}

Berdasarkan hasil pengolahan data, analisa dan pengamatan yang telah dilakukan pada kerja praktek di PT. Merck, Tbk., dapat ditarik beberapa kesimpulan sebagai berikut. Metode yang digunakan untuk meneliti penyebab rekonsiliasi adalah hipotesis statistik menggunakan pengujian Independent Sample T-Test. Pengujian rata-rata berat core tablet dengan rata-rata berat coated tablet menunjukkan bahwa proses sugar coating menyebabkan variasi pada berat secara signifikan karena prosesnya yang semi-otomasi sehingga faktor manusia menyebabkan variasi. Setelah dilakukan pengolahan data, proses blister packing dan packing sekunder tidak menyebabkan variasi secara signifikan. Setelah melakukan pengamatan, penulis memberikan saran kepada perusahaan mengenai proses produksi dan spesifikasi yang mempengaruhi perhitungan rekonsiliasi: perusahaan sebaiknya mengganti mesin sugar coating menjadi terotomasi sepenuhnya agar terdapat standar yang jelas mengenai proses sugar coating, dan perusahaan sebaiknya mengganti spesifikasi dari rekonsiliasi agar dapat mewakili seluruh hasil nyata yang terjadi pada finished goods.

\section{REFERENSI}

[1] Ghozali, Imam. (2012). Aplikasi Analisis Multivariate dengan Program IBM SPSS. Yogyakarta: Universitas Diponegoro.

[2] Hidayat, Baron, Fatma I. dan Muliadi. (2015). Implementasi Independent T-Test pada Aplikasi Pembelajaran Multimedia Ragam dan Gerak Seni Tari Daerah Kalimantan Selatan. Jurnal Ilmu Komputer 2(1), 11-21.

[3] Nasution, S. (2000). Metode Research. Jakarta: Bumi Aksara.

[4] Siegel, S. (1994). Statistik Non Parametrik Untuk Ilmu-Ilmu Sosial. Jakarta: PT. Gramedia.

[5] Walpole, R.E., R.H. Myers. (!995). Ilmu Peluang dan Statistika untuk Insinyur dan Ilmuwan Edisi ke-4. Bandung: Penerbit ITB 